\title{
Pancreatitis after sphincter of Oddi manometry
}

\author{
P Rolny, B Anderberg, I Ihse, E Lindström, G Olaison, A Arvill
}

\begin{abstract}
The nature, frequency, severity, and possible causes of complications after 207 sphincter of Oddi manometry measurements were studied in 146 patients. Acute pancreatitis was diagnosed in $6 \%$ ( 12 of 207 ) of the investigations and in $8 \%$ ( 12 of 146) of the patients examined. The pancreatitis was mild in all patients. After cannulation of the pancreatic duct, acute pancreatitis occurred in 10 of $95(11 \%)$ patients compared with one of $93(1 \%)$ when the manometry catheter entered the bile duct only $(p<0.02)$. Seven $(58 \%)$ of the patients who developed acute pancreatitis, however, were found to be suffering from chronic pancreatitis. Some $26 \%$ of all sphincter of Oddi manometry measurements on patients with this diagnosis were complicated by an acute attack of pancreatitis compared with $3 \%(\mathrm{p}<0.001)$ in patients without signs of chronic pancreatitis. In all patients the pancreatitis developed within three hours of manometry.

We conclude that pancreatitis may occasionally follow sphinter of Oddi manometry measurement, even in patients without pancreaticobiliary disease, and that underlying chronic pancreatitis constitutes a definite risk. Sphincter of Oddi manometry measurement in control subjects should therefore be performed only in centres where the safety of the procedure has been established, and the presence of chronic pancreatitis should be excluded beforehand. Cannulation of the pancreatic duct should be avoided. Manometry can be safely performed, however, as an outpatient procedure.
\end{abstract}

Although endoscopic manometry of the sphincter of Oddi has been increasingly used in clinical practice for more than a decade, very little is known about the nature, frequency, and severity of its complications. This is astonishing since experience from endoscopy with retrograde cholangiopancreatography (ERCP) shows that manipulation of the papilla as well as cannulation of the duct system, even without contrast injection, bears a small but definite risk of complications and in particular of acute pancreatitis.

We report on the complications we encountered in performing sphincter of Oddi manometry over a four year period.

\section{Patients and methods}

PATIENTS

This report is based on 207 consecutive manometric investigations of the sphincter of Oddi in 146 patients. The measurements were performed between 1984 and 1987. The patients had been referred because of postcholecystectomy right upper quadrant pain, suspected of being caused by biliary dyskinesia $(n=133)$ or because of chronic pancreatitis with suspected outflow obstruction $(n=13)$.

In addition to sphincter of Oddi manometry, the patients were also investigated by routine laboratory tests, liver tests, ultrasound, secretin test, upper gastrointestinal endoscopy, ERCP, and barium enema as indicated. The ERCP was always performed at least three weeks apart from manometry.

The patients were divided into the following groups based on results of these investigations as well as on a follow up period of at least one year.

Group 1 - patients with biliary dyskinesia $(n=24)$. The clinical suspicion was supported by grossly abnormal manometry findings. One patient, in whom cannulation of the papilla by the manometry catheter failed, was also included as surgical sphincteroplasty resulted in pain relief during the year of follow up.

Group 2 - patients with pain unrelated to the pancreaticobiliary region $(n=98)$. This group consisted of 88 patients with normal manometry measurements as well as eight patients in whom pull-through manometry failed. In our experience differentiation between normal and abnormal manometry results is clinically relevant as most patients with abnormal sphincter of Oddi pressure, if untreated, continued to experience pain, whereas those with normal results either improve over time or are diagnosed as having other diseases unrelated to the pancreaticobiliary region.

Group 3 - chronic pancreatitis $(n=24)$. In 13 of these patients the diagnosis had been established before manometry. These 13 suffered from episodes of upper abdominal pain lasting from some hours to several days and an outflow obstruction was suspected. The remaining 11 patients initially showed a clinical picture of biliary dyskinesia characterised by episodes of biliary-like pain. In these the diagnosis of chronic pancreatitis was established two to 14 months after the manometry procedure. The aetiology was alcohol in six and unknown in the remaining 18 patients. The diagnosis of chronic pancreatitis was, in accordance with internationally accepted criteria,' supported by at least two abnormal results from the following investigations: serum pancreatic-isoamylase, secretin test, ERCP, ${ }^{2}$ glucose tolerance test, and faecal fat excretion (when coeliac disease was excluded). In all of the patients manometry was performed during a quiet phase in the disease, at least four weeks after an exacerbation.

\section{ENDOSCOPIC MANOMETRY}

Because our method has already been described
Sweden.

Accepted for publication 18 September 1989 
in detail, ${ }^{3}$ only some points of major interest will be discussed here.

Before investigation the patients were sedated with intravenous diazepam $(2 \cdot 5-15 \mathrm{mg})$. As shown previously this drug does not exert any appreciable effect on the sphincter. ${ }^{+}$No other drugs were used. For duodenoscopy a standard fibre endoscope (Olympus JF1T) was used.

Between 1984 and 1985 the triple lumen manometry catheter was perfused with bubblefree water at a rate of $0.25 \mathrm{ml} /$ minute and between 1985 and 1987 with isotonic saline at the same rate. A minimally compliant hydraulic capillary infusion system was used. The cannulation procedure was regarded as easy if less than four attempts were needed to insert the cannula into the selected duct. Identification of the duct that had been cannulated was based on the appearance of colourless pancreatic juice or bile in the catheter upon gentle aspiration. The reliability of this method has been documented previously. $^{5}$

The pancreatic duct alone was cannulated on 56 occasions and both pancreatic and bile ducts on 39 occasions. Thus, the manometry catheter entered the pancreatic duct on a total of 95 occasions, and on 93 occasions the bile duct only was cannulated. Only one registration was performed from either duct at any manometry session. Two of the patients had three and $57 \mathrm{had}$ two manometry investigations at least two weeks apart, whereas the remaining 87 were investigated once only.

On most occasions the perfusion time of any duct did not exceed 20 minutes. It was longer (25-40 minutes) on only nine occasions in six patients.

The manometry was performed as an outpatient procedure with the patients remaining at the hospital for four to five hours for observation. Those who were not completely free of symptoms by that time were admitted to hospital until all their symptoms resolved. No food was allowed for the first three hours of observation but thereafter a cup of tea and a sandwich were offered.

DEFINITION OF POSTMANOMETRY

PANCREATITIS

Patients who developed upper abdominal pain accompanied by raised serum amylase or pancreatic isoamylase activities after the manometry procedure were classified as having acute pancreatitis. As neither serum amylase nor pancreatic isoamylase were determined in asymptomatic patients our definition comprises only clinically evident pancreatitis.

For statistical analysis a $\chi^{2}$ test was used, using Yates's correction.

\section{Results}

The only type of complication found was acute pancreatitis. Other complications such as sepsis, pseudocyst formation, cholangitis, or adult respiratory distress syndrome were not encountered.

Altogether 12 episodes of pancreatitis were recorded after 207 manometry procedures $(6 \%)$ in 146 patients $(8 \%)$. Pancreatitis developed in 11 of $188(5 \cdot 3 \%)$ investigations when the pancreatic duct or bile duct, or both, were cannulated and in one of $19(5 \cdot 2 \%)$ when the cannulation of the papilla failed.

According to accepted criteria ${ }^{6}$ the attacks of pancreatitis were clinically mild in all patients (Table I). The hospital stay ranged from four to 12 (mean eight) days. In none of the patients were any longterm complications detected clinically or by ultrasound or computed tomography.

As shown in Table I the intraductal pressures were normal or only slightly raised in the subjects who subsequently developed pancreatitis and remained unchanged during the manometry procedure. In four of the patients who developed pancreatitis the manometry catheter was perfused with bubble-free water and in nine the isotonic saline was used. The perfusion times in each of the patients are also shown in Table I.

In 10 of the 12 manometry investigations that were followed by pancreatitis, the pancreatic duct was cannulated with or without concommitant cannulation of the bile duct (Table I). When all the pull-through manometry investigations are considered, pancreatitis developed on 10 of $95(11 \%)$ occasions when the pancreatic duct was cannulated and on one of $93(1 \%)$ occasions when the bile duct only was cannulated $(\mathrm{p}<0.02)$ (Table II). Pancreatitis was not more frequent when both the pancreatic and bile ducts

TABLE I Clinical and manometrical characteristics in patients with postmanometry pancreatitis (PM)

\begin{tabular}{|c|c|c|c|c|c|c|c|c|c|}
\hline Patient & $P D P$ & PSOP & $\begin{array}{l}\text { Manometry } \\
\text { time }(\min )\end{array}$ & $B D P$ & BSOP & $\begin{array}{l}\text { Manometry } \\
\text { time }(\min )\end{array}$ & $\begin{array}{l}\text { Perfusion } \\
\text { fluid }\end{array}$ & $\begin{array}{l}\text { Severity } \\
\text { of PMP }\end{array}$ & Final diagnosis \\
\hline 1 & 9 & 12 & 10 & - & - & - & $\mathrm{H}_{2} \mathrm{O}$ & Mild & Chronic pancreatitis \\
\hline 2 & 8 & 10 & 12 & - & - & - & $\mathrm{H}_{2} \mathrm{O}$ & Mild & Chronic pancreatitis \\
\hline 3 & 18 & 18 & 11 & - & - & - & $\mathrm{H}_{2} \mathrm{O}$ & Mild & Chronic pancreatitis \\
\hline 4 & 16 & 32 & 9 & - & - & - & $\mathrm{NaCl}$ & Mild & Chronic pancreatitis \\
\hline \multirow[t]{2}{*}{5} & 8 & 10 & 7 & - & - & - & $\mathrm{H}_{2} \mathrm{O}$ & Mild & Chronic pancreatitis \\
\hline & 14 & 17 & 13 & & & & $\mathrm{H}_{2} \mathrm{O}$ & $\overline{M i l d}$ & \\
\hline 6 & 10 & 16 & $<1$ & 4 & 22 & 15 & $\mathrm{NaCl}$ & Mild & Unrelated pain \\
\hline 7 & 16 & nd & $<1$ & - & - & - & $\mathrm{NaCl}$ & Mild & Unrelated pain \\
\hline 8 & 18 & 20 & 10 & - & - & - & $\mathrm{NaCl}$ & Mild & Chronic pancreatitis \\
\hline 9 & 10 & 12 & 3 & - & - & - & $\mathrm{NaCl}$ & Mild & Chronic pancreatitis \\
\hline \multirow[t]{2}{*}{10} & - & - & - & - & - & - & $\mathrm{NaCl}$ & Mild & Biliary dyskinesia \\
\hline & $\overline{7}$ & - & - & $=$ & - & $=$ & $\mathrm{NaCl}$ & - & \\
\hline 11 & 17 & nd & 30 & 15 & 52 & 25 & $\mathrm{NaCl}$ & Mild & Biliary dyskinesia \\
\hline & 18 & nd & 30 & 19 & 15 & 25 & $\mathrm{NaCl}$ & - & \\
\hline 12 & - & - & - & 12 & 17 & 30 & $\mathrm{NaCl}$ & Mild & Unrelated pain \\
\hline
\end{tabular}

$\mathrm{PDP}=$ pancreatic duct pressure $(\mathrm{mmHg})$, norm $\leq 15$ 
TABLE II Postmanometry pancreatitis $(P M P)$ in relation to duct cannulated in patients with and without chronic pancreatitis

\begin{tabular}{|c|c|c|c|c|c|c|}
\hline \multirow[b]{2}{*}{ Diagnosis } & \multicolumn{2}{|c|}{$\begin{array}{l}\text { Pancreatic duct } \\
\text { cannulated }\end{array}$} & \multicolumn{2}{|c|}{$\begin{array}{l}\text { Bile duct } \\
\text { cannulated }\end{array}$} & \multicolumn{2}{|c|}{ Total } \\
\hline & No & $P M P N o(\%)$ & No & $P M P N o(\%)$ & No & $P M P N o(\%)$ \\
\hline $\begin{array}{l}\text { Chronic pancreatitis } \\
\text { Non-pancreatic disease } \\
\text { Total }\end{array}$ & $\begin{array}{l}22 \\
73 \\
95\end{array}$ & $\begin{array}{c}7(31 \cdot 8) \\
3(4 \cdot 1) \\
10(10 \cdot 5)\end{array}$ & $\begin{array}{r}5 \\
88 \\
93\end{array}$ & $\begin{array}{l}0(0) \\
1(1 \cdot 1) \\
1(1 \cdot 07)\end{array}$ & $\begin{array}{r}27 \\
161 \\
188\end{array}$ & $\begin{array}{c}7(27 \cdot 9) \\
4(2 \cdot 5) \\
11(10 \cdot 6)\end{array}$ \\
\hline
\end{tabular}

^Comprises all patients in whom the pancreatic duct alone or both pancreatic duct and bile duct were cannulated. tis occurred in $6.5 \%$ and $19 \%$ of subjects respectively. In addition, sepsis, pseudocysts, and adult respiratory distress syndrome were occasionally observed. ${ }^{8}$ Most of the authors, however, performed ERCP and manometry at the same session. Although no correlation was found between performing the procedures at different times or the order in which they were performed, ${ }^{8}$ the relative contribution of ERCP can not be disregarded. This report is the first comprehensive study of complications associated with sphincter of Oddi manometry. It is based on a comparatively large number of manometric investigations performed at least three weeks apart from ERCP. Thus, the findings are solely related to the manometry procedure.

In contrast to a previous report ${ }^{8}$ pancreatitis was the only complication occurring in the $6 \%$ of our manometric studies that were followed by complications. Although none of our patients experienced severe pancreatitis or any longterm sequelae, it caused a prolonged stay in hospital in four patients. Moreover, since pancreatitis can, irrespective of aetiology, worsen and become severe it is most important to look for possible causes.

An increase in intraductal pressure during the procedure was not found to be a causative factor in this study. Likewise, intraductal hypoosmolality has to be discarded as a factor since the frequency of pancreatitis was not affected by replacing water with isotonic saline for perfusion of the manometry catheter. On the other hand, cannulation of the pancreatic duct seems to constitute a risk as this duct was cannulated on all but two manometry procedures that were followed by pancreatitis. More than half the number of attacks, however, occurred in patients with chronic pancreatitis and this seems to be a major risk factor. This is important since in almost half of our patients the diagnosis of chronic pancreatitis was unknown at the time of manometry. Thus, chronic pancreatitis should be excluded before referring a patient for sphincter of Oddi manometry. On the other hand it is difficult to explain the high frequency of acute postmanometry pancreatitis in our patients with chronic pancreatitis, as ERCP in these subjects was followed by only one case $(4 \cdot 6 \%)$ of mild pancreatitis. Also, in our experience, which comprises nearly 7000 ERCP investigations, pancreatitis after ERCP is only slightly more frequent in patients with chronic pancreatitis than in those without that diagnosis.

Whether patients with biliary dyskinesia are at increased risk for postmanometry pancreatitis as suggested by King $e t a l^{9}$ cannot be judged from our study as pancreatitis followed only one of the pull-through manometry investigations in this patient group. In King's study, however, ${ }^{9}$ an unspecified number of patients with hyperamylasaemia were included and their findings may reflect a relatively high proportion of patients with pancreatitis rather than biliary dyskinesia.

Contrary to previous opinion, ${ }^{7}$ our results show that postmanometry pancreatitis may occasionally develop even in subjects without any underlying disease. A recent report of severe postmanometry pancreatitis in a healthy volun-

ntil recently endoscopic manometry cedure that is oddi has been regarded as Then it was stated at the international workshop on sphincter of Oddi in Rome in 1985 that pancreatitis could occasionally occur in patients with pancreatic or biliary abnormalities or when manometry was performed in conjunction with ERCP. ${ }^{7}$ In two recent studies, ${ }^{89}$ so far published in abstract form only, postmanometry pancreati- 
teer $^{10}$ supports our findings. Although this report does not mention which duct was cannulated, what is remarkable is that the total cannulation time was only seven minutes. This is consistent with our observation that short manometry by no means prevents postmanometry pancreatitis. On the other hand, our results suggest that the risk is negligible, irrespective of underlying disease, if only the bile duct is cannulated. Although our study does not suggest that the mechanical trauma, due to repeated attempts at cannulation or repeated cannulation, increases the risk, this cannot be definitely excluded. Furthermore, such a technique carries a risk of manometric artefacts and should also, for this reason, be avoided.

Our observation that postmanometry pancreatitis developed invariably within three hours of manometry is also clinically important as it suggests that the procedure may safely be done on an outpatient basis. Finally, our results suggest that sphincter of Oddi manometry in healthy volunteers should only be undertaken in centres where the safety of the procedure has been established.
We thank Mrs Ann-Charlott Sundh-Persson for excellent secretarial work, Derek Filbey for correcting the English, and Ander Ärlebäck for skilful technical assistance.

1 Sarles H. Etiopathogenesis and definitions of chronic pancreatitis. Dig Dis Sci 1986; 31: 915-1075.

2 Axon ATR, Classen M, Cotton PB, Cremer M, Freeny PC Lees WR. Pancreatography in chronic pancreatitis: interLees WR. Pancreatography in chronic pa
national definitions. Gut 1984; 25: 1107-12.

3 Rolny P, Ärelbäck A, Funch-Jensen P, Kruse A, Ravnsbaeck J, Järnerot $G$. Paradoxical response of sphincter of Oddi to intravenous injection of cholecystokinin or ceruletide. Manometric findings and results of treatment in biliary dyskinesia. Gut 1986; 27: 1507-11

4 Staritz M. Pharmacology of the sphincter of Oddi. Endoscop 1988; 20: $171-4$.

5 Carr-Locke DL, Gregg JA. Endoscopic manometry of pancreatic and biliary sphincter zones in man. Basal results in healthy volunteers. Dig Dis Sci 1981; 26: 7-15.

6 Ranson JHC, Rifkind KM, Turner JW. Prognostic signs and non-operative peritoneal lavage in acute pancreatitis. Surg non-operative peritoneal lavage

7 Carr-Locke DL. Sphincter of Oddi manometry: the control population. Ital f Gastroenterol 1985; 17: 341-3.

8 Cattau EL Jr, Johnson DA, Benjamin SB, Geenen JE, Hogan WJ. Sphincter of Oddi manometry: a survey of method ology, complications and clinical application. Gastrointes Endosc 1988; 34: 185 .

9 King CE, Kalvaria I, Sninsky CA. Pancreatitis due to endoscopic biliary manometry: proceed with caution. Gastroenterology 1988; 94: A227.

10 Albert MB, Steinberg WM, Irani SK. Severe acute pancreatitis complicating sphincter of Oddi manometry. Gastrointest Endosc 1988; 34: 342-5. 